\title{
Expressions and clinical significances of CD133 protein and CD133 mRNA in primary lesion of gastric adenocacinoma
}

\author{
Ji-wei $\mathrm{Yu}^{1 \dagger}$, Peng Zhang ${ }^{1,2+}$, Ju-gang Wu${ }^{1}$, Sheng-hua $\mathrm{Wu}^{1}$, Xiao-qiang $\mathrm{Li}^{3}$, Shi-ting Wang ${ }^{4}$, Rui-qi Lu', \\ Xiao-chun $\mathrm{Ni}^{1}$, Bo-jian Jiang ${ }^{1 *}$
}

\begin{abstract}
Background: To study on expressions and clinical significances of CD133 protein and CD133 mRNA in primary lesion of gastric adenocarcinoma (GC).

Methods: Expressions of CD133 protein by immunostaining (99 cases) and CD133 mRNA by semi-quantitative RT-PCR (31 cases) were detected in primary lesion and in noncancerous gastric mucosa tissue (NCGT). Correlations of CD133 protein expression with clinicopathological parameters and post-operative survival were analyzed. Relations of CD133 mRNA level with Ki-67 labeling index (LI), and lymphatic metastasis were assessed too.

Results: Brown particles indicating CD133 protein positivity occurred in some parts of tumor cells and epithelium. Expressive percentage of CD133 protein positivity was significantly higher in subgroups with $>5 \mathrm{~cm}$ diameter $(P=0.041)$, later TNM stage $(P=0.044)$, severer lymph node metastasis $(P=0.017)$, occurrences of lymphatic invasion $(P=0.000)$ and vascular invasion $(P=0.000)$ respectively. Severer invasion depth $(P=0.011)$, lymph node metastasis occurrence $(P=0.043)$ and later TNM stage $(P=0.049)$ were the independent risk factors for CD133 protein expression. Average brightness scale value (BSV) of CD133 mRNA was significantly higher in subgroups with $>5 \mathrm{~cm}$ diameter $(P=0.041)$, lymph node metastasis occurrence $(P=0.004)$ and in lower $\mathrm{Ki}-67 \mathrm{LI}(P=0.02)$. Relative analysis revealed that BSV of CD133 mRNA related positively to metastatic lymphatic nodes ratio $(P=0.008)$ and metastatic lymph node number $(P=0.009)$, but negatively to Ki-67 LI $(P=0.009)$. Survival of positive subgroup of CD 133 protein was significantly poorer $(P=0.047)$. Lymph node metastasis occurrence $(P=0.042)$, later TNM stage $(P=0.046)$ and CD 133 protein positive expression $(P=0.046)$ were respectively the independent risk factors to survival.

Conclusion: Higher expressive level of CD133 mRNA is associated to lower Ki-67 LI and severer lymphatic metastasis. Therefore, the expressive level of CD133 mRNA can play an appropriate role to reflect the status of lymph node metastasis and proliferation of GC. CD133 protein expression is closely related with larger tumor, later TNM stage, lymphtic metastasis and survival of GC.
\end{abstract}

\section{Background}

Gastric cancer is among the most common form of cancer of the digestive system with an estimated incidence of approximately 22000 cases in the USA for 2008 [1], and is still one of the most common cancer-related causes of death in the world, particularly in Asian countries [2]. Worldwide, gastric carcinoma is the third most common

\footnotetext{
* Correspondence: Jiang-bj2102@hotmail.com

+ Contributed equally

'Department of General Surgery, No. 3 People's Hospital, Shanghai Jiao-tong University School of Medicine, Shanghai 201900, China

Full list of author information is available at the end of the article
}

form of cancer with overall 5-year survival rate of less than $20 \%$ as most patients are diagnosed late and are unsuitable for curative surgery. With the challenge of disseminated disease at the time of diagnosis, there is a critical need for finding more effective ways to eradicate the cancer cells. However, the process of cancer initiation, metastasis and recurrence is sequential and selective, and consists of a series of independent steps with interlinks [3-6].

Reportedly, CD133 expressing cells in glioblstoma and colorectal cancers include, but are apparently not limited to, the small subpopulation of tumor cells termed 
as cancer stem cells (CSCs) which mediate tumor initiation, metastasis and recurrence [4-6], and possess the unique self-renewal properties, the multiple differentiating potential, the proliferating aptitude and the carcinogenesis $[5,7,8]$. In addition to being considered as the tumor initiating cell population, CSCs have also been demonstrated to resistance to chemotherapy and radiotherapy implying that they are responsible for tumor recurrence $[9,10]$. At the same time, CD133 has been considered as a CSCs marker in many kinds of tumors such as colorectal $[5,6]$, brain $[4,7]$, prostate [8], pancreatic [11] and gastric cancers [12].

One of the aims in this study was to investigate the expression levels of CD133 protein and CD133 mRNA in primary lesion of gastric adenocarcinoma $(\mathrm{GC})$ and to compare these expressive levels with clinicopathological characteristics and survival time after curative resection. Additionally, we explored the relation of CD133 mRNA expression level with lymphatic vessel infiltration, lymph node metastasis and metastatic lymph node ratio [13] which factors reflected the status of lymphatic metastasis demonstrated wildly as one of the main risk factors for the prognosis. At the same time, immunostaining for Ki-67, a kind of cellule nucleus protein, and its labeling index (LI) were applied to assess the proliferating ability of tumor cells with higher or lower CD133 mRNA level and the relation of this proliferating ability of tumor cells sharing higher or lower CD133 mRNA level were evaluated.

\section{Methods \\ Patients}

A total of 99 patients who underwent radical gastrectomy $\left(D_{2}\right.$ or $D_{3} ; R_{0}$ or $R_{1}$ ) for primary GC at our hospital from July 2004 to July 2009 were registered for immunohistochemical staining in this study. The median age of the patients was 62.0 years old (range 29 83 years old) in this group of patients. Among them, a total of 31 patients from May 2008 to July 2009 were also assessed by semiquantitative RT-PCR for detecting CD133 mRNA in primary lesion and in noncancerous gastric tissue (NCGT), which was identified by pathological observation, at $>5$ $\mathrm{cm}$ distance adjacent to primary lesion, and by immunohistochemical staining for Ki-67 expression in tumor cells. In this group of patients, the median age of the patients was 64.0 years old (range 34 83 years old). None of them accepted any preoperative chemotherapy or radiotherapy. All of the cases received postoperative adjuvant chemotherapy. The diameter of tumors was ranged from 1 to $10 \mathrm{~cm}$; median $5.0 \mathrm{~cm}$. Preoperative informed consent was obtained from each patient included in the study in accordance with institutional guidance. Half specimen from primary lesion or NCGT was fixed in $10 \%$ buffered formalin and embedded in paraffin. In this part of sample, full layer of gastric wall was included for next stainings. Three sections from each sample of primary lesion were serially cut for HE staining, CD133 and Ki-67 immunostainings. Another half specimen, mainly from the selected mucosa layer was used for PCR detection, was fixed in fluid nitrogen and then stored in $-80^{\circ} \mathrm{C}$ until use. This study was approved by ethic committee of our hospital before its start.

\section{Immunohistochemical and pathological examinations}

Serial tissue sections with $4 \mu \mathrm{m}$ were stained for CD133 (CD133/1 monoclonal antibody; 1:40 dilution, Miltenyi Biotec $\mathrm{GmbH}$, Bergisch Gladbach, Germany) by ABC method (mouse ABC Staining System, sc-2017, Santa Cruz Biotechnology Co, CA, USA), Ki-67 (mouse against to human of monoclonal antibody, Changdao Biotech, Co., Shanghai, China) by two steps method [14] and HE section. In details for CD133 immunostaining, sections were dewaxed, and rehydrated by sequential immersion in xylene, graded ethanol, and water. Antigen retrieval was done by heating the slides in microwave oven in $0.01 \mathrm{mmol} / \mathrm{L}$ citrate buffer ( $\mathrm{pH} 6.0$ ). After washing in phosphate-buffered saline (PBS), the slides were exposed to $10 \%$ normal blocking serum (Santa Cruz Biotechnology, CA, USA) for $10 \mathrm{~min}$ to reduce the nonspecific antibody binding Endogenous peroxidase activity was blocked by $3 \%$ hydrogen peroxide in methanol for $30 \mathrm{~min}$. Incubation with primary antibody of CD133 (50 ul, 1:40 dilution) was performed for one hour at room temperature. And then, immunodetection was performed by $\mathrm{ABC}$ staining system according to the production instructions. Primary antibodies were visualized with DAB solution (Santa Cruz Biotechnology Co, CA, USA). Finally, slides were couterstained with haematoxylin to show the nucleus of cells clearly. Cells with brown color as CD133 protein expression in the gland parietes, the cellular membrane surface and the epithelium were considered as positivity of CD133 immunostaining. Negative controls for CD133 and Ki-67 were carried out as above by substituting normal serum for the primary antibodies. Sections from previously studied cases of GC known to positive expression were used as positive controls. Positive percentage as $\mathrm{Ki}-67 \mathrm{LI}$ was calculated according to the positive cells number in 1000 counted cells number under $\times 400$ magnifications in 5 fields freely selected under a light microscope [14]. All sections were observed and scored by two independent investigators blind to each patient's status.

\section{RNA isolation and reverse transcriptase polymerase chain reaction (RT-PCR)}

Total RNA was extracted from $80-100 \mathrm{mg}$ frozen GC tissue treated with RNA PCR Kit (TaKaRa Biotechnology, Tokyo, Japan) following the manufacturer suggested protocols. Oligo dT-Adaptor Primer was used with 
AMV reverse transcriptase XL for cDNA synthesis from 500 ng of total RNA. PCR was conducted with TaKaRa Ex Taq HS DNA polymerase in $50 \mu$ l reaction volumes. Primers (synthesized by Sangon Technology, Shanghai, China) used were including GAPDH (sense, 5'-ACGGATTTGGTCGTATTGGGCG-3'; antisense, 5'-CTCCT GGAAGATGGTGATGG-3') with a product length of 197 bp and CD133 (sense, 5'-TTACGGCACTCTTCACCT-3'; antisense, 5'-TATTCCACAAGCAGCAAA3 ) with a product length of $172 \mathrm{bp}$. The reactions were conducted for GAPDH as the internal control under the following conditions: initial denaturing step at $95^{\circ} \mathrm{C}$ for $1 \mathrm{~min}, 28$ cycles of $95^{\circ} \mathrm{C}$ for $1 \mathrm{~min}, 55^{\circ} \mathrm{C}$ for $1 \mathrm{~min}, 72^{\circ} \mathrm{C}$ for $1 \mathrm{~min}$, followed by $72^{\circ} \mathrm{C}$ for $10 \mathrm{~min}$; For CD133: initial denaturing step at $94^{\circ} \mathrm{C}$ for $2 \mathrm{~min}, 28$ cycles at $94^{\circ} \mathrm{C}$ for 30 seconds, $51^{\circ} \mathrm{C}$ for 30 seconds, $72^{\circ} \mathrm{C}$ for 30 seconds, followed by $72^{\circ} \mathrm{C}$ for $10 \mathrm{~min}$. according to the manufacturer's instruction Five $\mu \mathrm{l}$ CD133 PCR and $2 \mu \mathrm{l}$ of the products amplified by MyCycler ${ }^{\text {Tw }}$ Thermal Cycler (Bio-Red Laboratories, CA, USA) were separated on a $1.5 \%$ agarose gel (Gene Tech, Shanghai, China) by electrophoresis apparatus (Tunon, EpS 100, Shanghai Tianneng Tech Co. Shanghai, China). Digital images to exposure the occurrence of CD133 mRNA as a white target strip were captured on a gel documentation system (UNIVERSAL HOOD II, Bio-Red Laboratories, Segrate, Milan, Italy). Imaging assessments to measure the brightness scale value (BSV) of CD133 automatically from the write strip and to compared the relative ratio between CD133 strip and control strip were carried out by Quantity One 1-D analysis software (The Discoveries $^{\mathrm{mat}}$ Quantity One 1-D Analysis Software Version 4.5, Bio-Red Laboratories, CA, USA.).

\section{Clinicopathological assessments}

Clinicopathological parameters included gender, age, tumor size histological grade, invasion depth, lymph node metastasis, TNM stage, lymphatic vessel infiltration, vascular infiltration and metastatic lymph node ratio for CD133 protein and CD133 mRNA assessments respectively $[13,15]$, mainly according to UICC classification [15]. And Ki-67 LI was also used in the evaluation of CD133 mRNA expression.

\section{Prognostic analysis}

The deadline of follow-up for 99 patients was until November 2009, and the average survival time was $26.76 \pm 17.02$ months. A total of 9 cases (9.1\% patients) lost in follow-up period. In this registered group, 39 cases died of the recurrence of gastric cancer, vascular diseases of brain or heart, or complications after surgery respectively. All patients in this group for survival assessment were divided as positive or negative subgroup of CD133 immunostaining.

\section{Statistics}

All statistical analyses were performed with the SPSS software version 13.0 (SPSS, Chicago, IL, USA). The correlations between expression of CD133 protein and clinicopathological parameters were assessed with the chi-squared test as a univariate analysis. Furthermore, the multivariate analysis was carried out with Logistic analysis for these correlations in order to explain the more important significances of the observed parameters. CD133 mRNA data was expressed as means \pm SD, and statistical analysis was carried out using Student's $t$ test. Relative evaluations of CD133 mRNA level with several clinicopathological data were made by Spearman's rho analysis. The Kaplan-Meier method was used to estimate survival as a function of time, and survival differences were analyzed by Log-rank test. The Cox regression model was used for multivariate analysis of prognostic factors. In all of the tests, a $P$ value less than 0.05 was considered to be statistically significant.

\section{Results}

\section{CD133 protein expression in primary lesion}

Particles sharing brown color indicated to CD133 protein expression occurred in some parts of gland parietes, cellular membrane surface of some tumor cells and some epithelium in primary lesion, in which CD133 positive particles mainly located in some parts of tumor cells in the mucosa and the submucosa layers (Figure $1 \mathrm{C}$ and 1D). Some CD133 positive cells were identified in the wall of crypts and in the cancerous emboli in vessel-like structures in primary lesion (Figure $1 \mathrm{E}$ and $1 \mathrm{~F}$ ). No positive staining was seen in NCGT as control subgroup (Figure 1B), which positivity rate of CD133 (0\%) was significantly lower than that in cancerous subgroup $(29.3 \%$, 29 cases/99 cases, $P=0.000$ ).

\section{Correlation of CD133 protein expression with clinicopathological parameters}

CD133 expression was significantly correlated with tumor diameter of $>5 \mathrm{~cm}(P=0.041)$, severer lymph node metastasis $(P=0.017)$, later TNM stage $(P=0.044)$, occurrences of lymphatic vessel infiltration $(P=0.000)$ and vascular infiltration $(P=0.000)$ (Table 1$)$. Furthermore, with the increase of invasion depth of tumor, the expressive rate of CD133 raised obviously, but no statistical significance. However, further stratified analysis revealed that the expressive rate of CD133 in subgroup of $\mathrm{T}_{3}-\mathrm{T}_{4}$ (6.06\%, 6 cases/99 cases) was significantly higher than that in subgroup of $\mathrm{T}_{1}-\mathrm{T}_{2}(23.23 \%, 23$ cases/99 cases, $P=0.038)$. The multivariate evaluation by Logistic analysis demonstrated that invasion depth $(P=0.011)$, lymph node metastasis $(P=0.043)$ and TNM stage $(P=$ 0.049 ) were the independent risk factors for CD133 protein expression respectively (Table 2 ). 

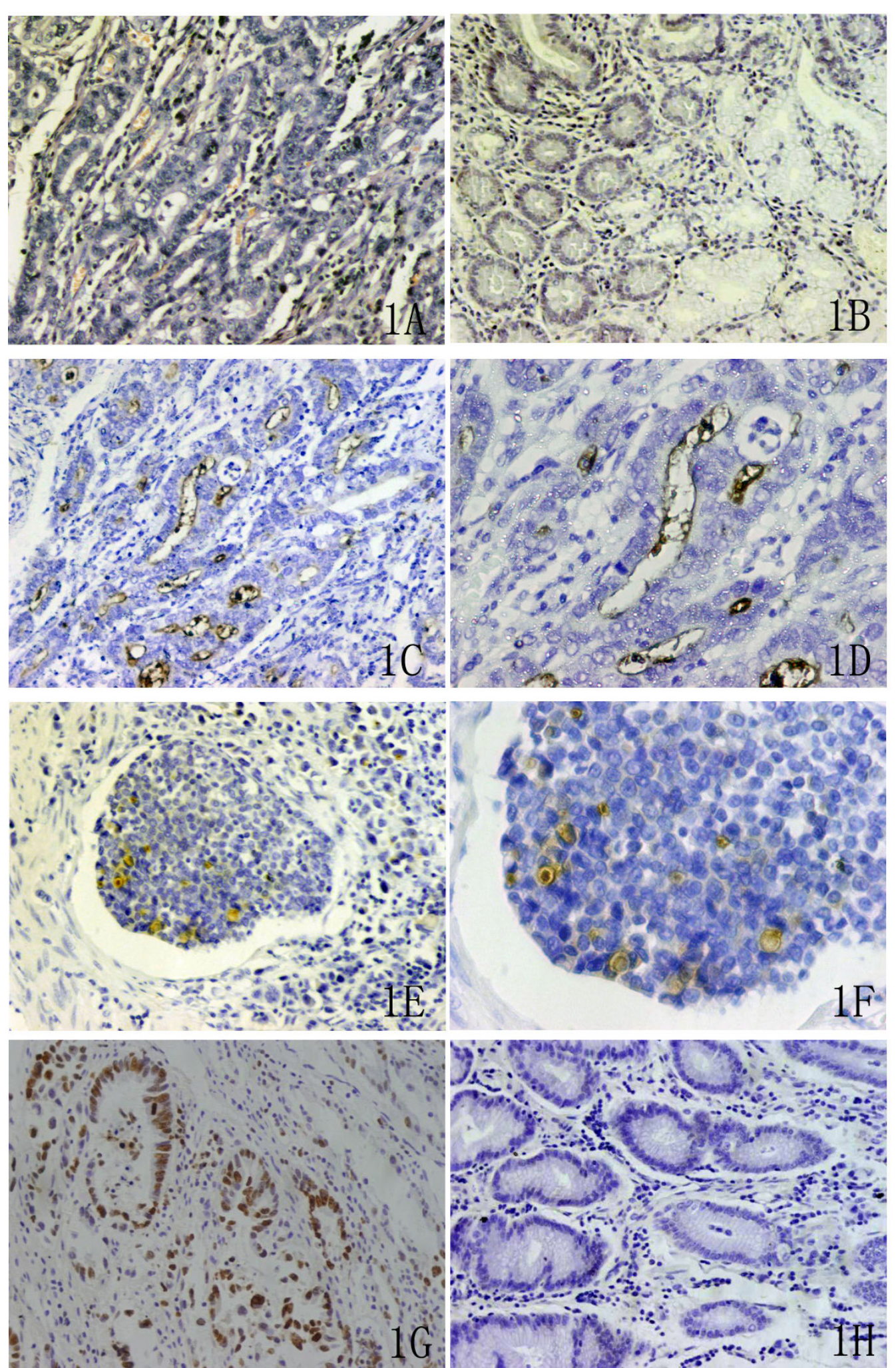

Figure 1 Morphological observation on the tumor cells with CD133 protein and Ki-67 immunostainings in primary lesion. Note: $A$ showed HE staining for GC tissue (×200). B showed CD133 immunostaining for NCGT (×200). C (×200) and D ( $\times 400)$ showed CD133 immunostaining for GC tissue. $\mathrm{E}(\times 200)$ and $F(\times 400)$ showed tumor cells with CD133 positivity in the cancerous emboli in vessel-like structure. G $(\times 200)$ and $H(\times 200)$ showed the higher positive and the lower positive expressions of Ki-67 immunostaining $(\times 200)$ respectively. 
Table 1 Correlation between CD133 protein expression and clinicopathological features [n(\%)](n=99 cases)

\begin{tabular}{|c|c|c|c|c|c|}
\hline \multirow[t]{2}{*}{ Clinicopathological parameter } & \multirow[t]{2}{*}{ Grouping } & \multicolumn{2}{|c|}{ CD133 protein expression } & \multirow[t]{2}{*}{$\chi^{2}$ value } & \multirow[t]{2}{*}{$P$ value } \\
\hline & & positive & negative & & \\
\hline \multirow[t]{2}{*}{ Gender } & male & 18(18.18) & $51(51.52)$ & 1.130 & 0.288 \\
\hline & female & $11(11.11)$ & 19(19.19) & & \\
\hline \multirow[t]{2}{*}{ Age(year) } & $\leq 60$ & $9(9.09)$ & $30(30.30)$ & 1.200 & 0.273 \\
\hline & $>60$ & $20(20.20)$ & $40(40.40)$ & & \\
\hline \multirow[t]{2}{*}{ Tumor diameter $(\mathrm{cm})$} & $\leq 5$ & $17(17.17)$ & $40(40.40)$ & 4.175 & 0.041 \\
\hline & $>5$ & $12(12.12)$ & 10(10.10) & & \\
\hline \multirow[t]{3}{*}{ Histological grade } & 1 & $5(5.05)$ & 16(16.16) & 2.030 & 0.566 \\
\hline & 2 & 13(13.13) & $27(27.27)$ & & \\
\hline & 3 & $11(11.11)$ & $27(27.27)$ & & \\
\hline \multirow[t]{4}{*}{ Invasion depth } & $\mathrm{T}_{1}$ & $0(0.00)$ & 11(11.11) & 6.116 & 0.106 \\
\hline & $\mathrm{T}_{2}$ & $6(6.06)$ & $17(17.17)$ & & \\
\hline & $\mathrm{T}_{3}$ & 10(10.10) & $21(21.21)$ & & \\
\hline & $\mathrm{T}_{4}$ & 13(13.13) & $21(21.21)$ & & \\
\hline \multirow[t]{4}{*}{ Lymph node metastasis } & $\mathrm{N}_{0}$ & $3(3.03)$ & $27(27.27)$ & 10.227 & 0.017 \\
\hline & $N_{1}$ & 15(15.15) & $20(20.20)$ & & \\
\hline & $\mathrm{N}_{2}$ & $7(7.07)$ & 19(19.19) & & \\
\hline & $\mathrm{N}_{3}$ & $4(4.04)$ & $4(4.04)$ & & \\
\hline \multirow[t]{4}{*}{ TNM stage } & $\|$ & $2(2.02)$ & 19(19.19) & 8.108 & 0.044 \\
\hline & III & $4(4.04)$ & 10(10.10) & & \\
\hline & IV & 13(13.13) & $31(31.31)$ & & \\
\hline & IV & 10(10.10) & 10(10.10) & & \\
\hline \multirow[t]{2}{*}{ Lymphatic vessel infiltration } & positive & $28(28.28)$ & $27(27.27)$ & 27.636 & 0.000 \\
\hline & negative & $1(1.01)$ & 43(43.43) & & \\
\hline \multirow[t]{2}{*}{ Vascular infiltration } & positive & $28(28.28)$ & 15(15.15) & 46.624 & 0.000 \\
\hline & negative & $1(1.01)$ & $55(55.56)$ & & \\
\hline
\end{tabular}

CD133 mRNA expressions in primary lesion and in NCGT The semi quantitative RT-PCR detection in 31 patients was performed to confirm the expressions of CD133 mRNA in primary lesion (100.0\%) and NCGT (16.1\%, 5 cases $/ 31$ cases $)\left(\chi^{2}=15.125, P=0.000\right)$ (Figure $2 \mathrm{~A}$ ). Average BSV of CD133 mRNA was $0.3783 \pm 0.1411$ in primary lesion subgroup and $0.0381 \pm 0.0919$ in NCGT subgroup respectively $(Z=-6.533, P=0.000$ ) (Figure 2B). In comparison with average BSV of CD133 mRNA in NCGT subgroup, the increasing range of average
BSV of CD133 mRNA was up to $993 \%$ in primary lesion subgroup.

\section{Correlation of BSV of CD133 mRNA with} clinicopathological parameters and Ki-67 LI

BSV of CD133 mRNA was significantly correlated with tumor diameter of $>5 \mathrm{~cm}(P=0.041)$ and severer lymph node metastasis $(P=0.004)$ (Table 3$)$. Relative analysis showed the BSV of CD133 mRNA rose with the increment of either the metastatic lymph node number

Table 2 Logistic analysis on the correlation of CD 133 protein expression with clinicopathological parameters ( $\mathrm{n}=99$ cases)

\begin{tabular}{|c|c|c|c|c|c|c|c|}
\hline Parameter & B & SE & Wald & df & Sig. & $\operatorname{Exp}(B)$ & $95.0 \% \mathrm{Cl}$ for $\operatorname{Exp}(\mathrm{B})$ \\
\hline Gender & 0.012 & 0.017 & 0.201 & 1 & 0.328 & 1.003 & $0.972 \sim 7.873$ \\
\hline Age(year) & 0.007 & 0.018 & 0.158 & 1 & 0.691 & 1.007 & $0.875 \sim 3.125$ \\
\hline Tumor diameter(cm) & 0.209 & 0.123 & 2.908 & 1 & 0.088 & 1.233 & $1.334 \sim 8.911$ \\
\hline Invasion depth & -1.238 & 0.488 & 6.430 & 1 & 0.011 & 0.290 & $1.079 \sim 12.381$ \\
\hline Histological grade & 0.181 & 0.281 & 0.414 & 1 & 0.520 & 1.198 & $0.987 \sim 3.212$ \\
\hline Lymph node metastasis & -0.929 & 0.459 & 4.102 & 1 & 0.043 & 0.395 & $1.156 \sim 18.324$ \\
\hline TNM stage & 1.048 & 0.636 & 2.720 & 1 & 0.049 & 2.853 & $1.138 \sim 14.216$ \\
\hline Lymphatic vessel infiltration & 0.847 & 0.601 & 1.568 & 1 & 0.067 & 3.213 & $1.335 \sim 10.954$ \\
\hline Vascular infiltration & 0.760 & 0.662 & 1.317 & 1 & 0.251 & 2.137 & $0.991 \sim 6.872$ \\
\hline
\end{tabular}




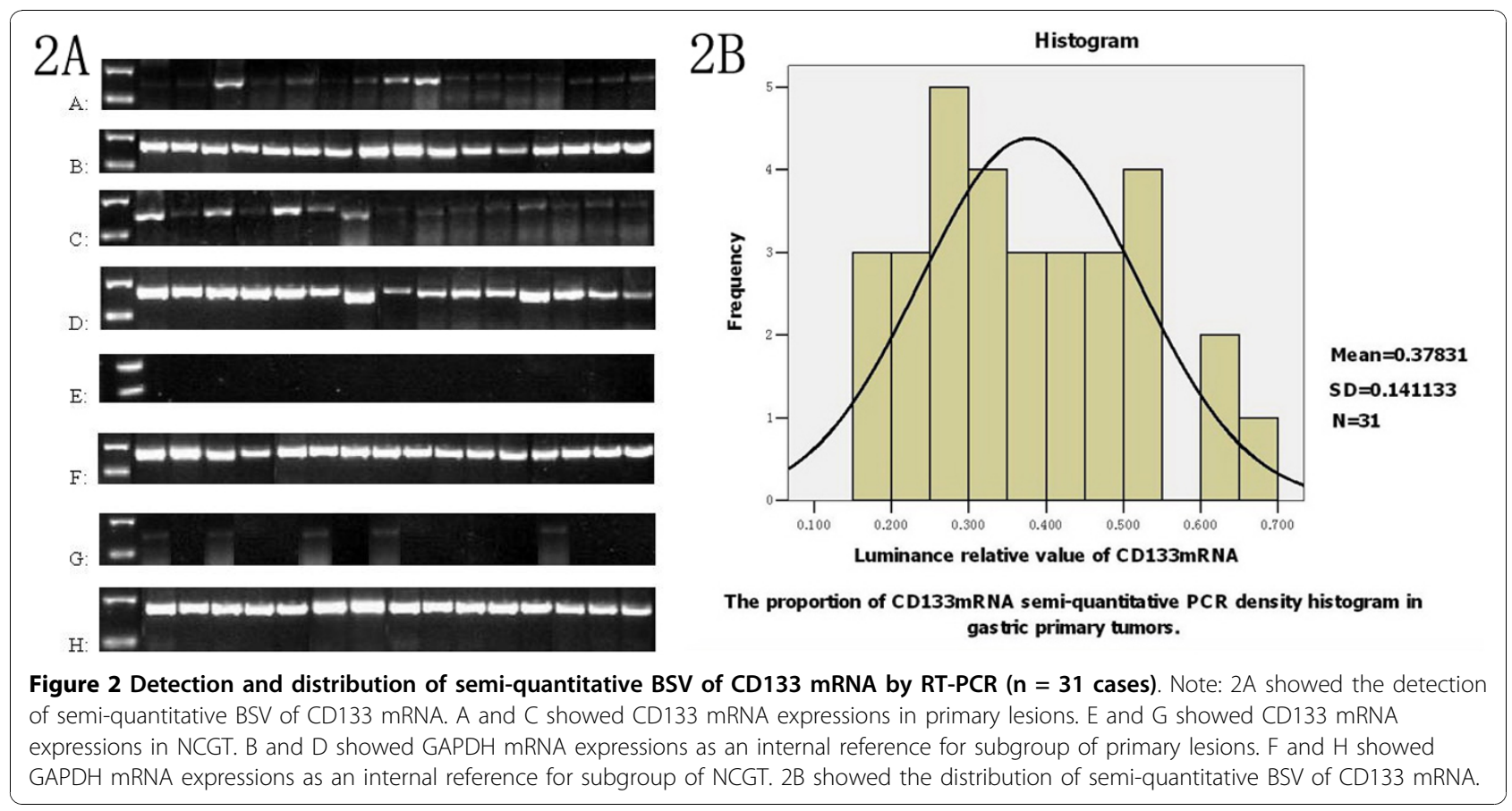

$(P=0.009)$ or the metastatic lymph node ratio $(P=$ 0.008 ) (Figure $3 \mathrm{~A}$ and $3 \mathrm{~B}$ ).

Positive staining of $\mathrm{Ki}-67$ occurred in nuclei of tumor cells as sharing brown color (Figure 1G). Because average LI of Ki-67 was $(36.6 \pm 30.5) \%$ in 31 patients, this value of $36.6 \%$ was applied as the bound dividing low (51.61\%, 16 cases/31 cases) and high (48.39\%, 15 cases/ 31 cases) subgroups of Ki-67 LI [14]. BSV of CD133 mRNA in low subgroup of Ki-67 LI (0.4364 \pm 0.1398$) \%$ was significantly higher than that in high subgroup of Ki-67 LI $(0.3164 \pm 0.1174 \%, P=0.020)$ (Table 3$)$. With the increment of Ki-67 LI, BSV of CD133 mRNA gradually decreased to show the negative relation (Figure $3 \mathrm{C}$ ).

\section{Prognostic analysis}

Univariate assessment revealed that the average survival time was $(22.76 \pm 13.476)$ months in CD133 positive subgroup while $(28.41 \pm 18.078)$ months in negative subgroup $(P=0.000$, Figure 4$)$. Further investigation by multivariate analysis showed that lymph node metastasis occurrence $(P=0.042)$, later stage of TNM $(P=0.046)$ and CD133 positive $(P=0.046)$ were the independent risk factors to survival respectively (Table 4 ).

\section{Discussion}

CD133/prominin-1, a pentaspan transmembrane glycoprotein, has been initially described as a surface antigen specially to human hematopoietic stem cells [16] and CSCs with CD 133 positivity have been implicated in tumor progress as identified in tumor growth of pancreatic [11] and colon cancers [4]. AC133, i.e. CD133, polypeptide has a predicted size of $97 \mathrm{kD}$ and contains five-transmembrane (5-TM) domains with an extracellular N-terminus and a cytoplasmic C-terminus. Whereas the expression of tetraspan (4-TM) and 7-TM molecules is well documented on mature and immature hematopoietic cells and leukocytes, this 5-TM type of structure containing two large (255-amino acid [aa] and 290-aa) extracellular loops is unique and does not share sequence homology with any known multi-TM family members [16]. Nowadays, CD133 presentation was found in many solid tumors such as brain tumor [4,7], prostate [8], pancreatic [11], hepatocellular [12] and colon cancers [5,6], but the specific role of these CSCs in tumor biology, including metastasis and recurrence, is still uncertain, especially in human GC. Although there are different phenotypes in different kinds of CSCs, the higher expression of CD133 as same phenotypes has been identified in CSCs, especially in solid tumors derived from epithelium cells of gastrointestinal organs [5-7,12,17]. O'Brien and his team [4] identified CD133 positive cells shared the characteristics of human colon cancer-initiating cells, in which CD133 positive cells were able to initiate tumor growth in minor quantity of the cells Moreover, CSCs with CD133 positivity possessed strong carcinogenesis, cloning ability and proliferating capacity as demonstrated in many experiments [4-8,11,12,17], and were resistant to anti-cancer therapy $[10,18]$. Hence, the metastasis and recurrence of cancer as one of main factors inflecting on the prognosis has still been hard to be overcome thoroughly until now.

Regulation and control on gene expression is partially dependent on the transcript and the protein expression 
Table 3 Correlation between BSV of CD133 mRNA with clinicopathological features and Ki-67 LI [n(\%)] ( $\mathrm{n}=31$ cases)

\begin{tabular}{|c|c|c|c|c|c|}
\hline Parameter & Grouping & $n(\%)$ & Mean \pm SD & Test value & $P$ value \\
\hline \multirow[t]{2}{*}{ Gender } & male & $24(77.4 \%)$ & $0.3674 \pm 0.1292$ & $Z=-0.520$ & 0.603 \\
\hline & female & $7(22.6 \%)$ & $0.4156 \pm 0.1829$ & & \\
\hline \multirow[t]{2}{*}{ Age(year) } & $\leq 60$ & $10(32.3 \%)$ & $0.3150 \pm 0.1140$ & $Z=-1.648$ & 0.099 \\
\hline & $>60$ & $21(67.7 \%)$ & $0.4084 \pm 0.1452$ & & \\
\hline \multirow[t]{2}{*}{ Tumor diameter $(\mathrm{cm})$} & $\leq \mathbf{5}$ & $18(58.1 \%)$ & $0.3343 \pm 0.1212$ & $Z=-2.042$ & 0.041 \\
\hline & $>5$ & $13(41.9 \%)$ & $0.4393 \pm 0.1484$ & & \\
\hline \multirow[t]{3}{*}{ Histological grade } & 1 & $3(9.7 \%)$ & $0.2555 \pm 0.0095$ & $H=3.501$ & 0.321 \\
\hline & 2 & $13(41.9 \%)$ & $0.3674 \pm 0.1185$ & & \\
\hline & 3 & $15(48.4)$ & $0.4177 \pm 0.1634$ & & \\
\hline \multirow[t]{4}{*}{ Invasion depth } & $\mathrm{T}_{1}$ & $1(3.2 \%)$ & $0.2630 \pm 0.0311$ & $H=3.142$ & 0.370 \\
\hline & $\mathrm{T}_{2}$ & $5(16.1 \%)$ & $0.3199 \pm 0.1855$ & & \\
\hline & $T_{3}$ & $13(41.9 \%)$ & $0.4234 \pm 0.1511$ & & \\
\hline & $\mathrm{T}_{4}$ & $12(38.7 \%)$ & $0.3634 \pm 0.1073$ & & \\
\hline \multirow[t]{4}{*}{ Lymph node metastasis } & $\mathrm{N}_{0}$ & $8(25.8 \%)$ & $0.2395 \pm 0.0309^{*}$ & $H=13.583$ & 0.004 \\
\hline & $N_{1}$ & 12(38.7\%) & $0.4418 \pm 0.1617$ & & \\
\hline & $\mathrm{N}_{2}$ & $7(22.6 \%)$ & $0.4258 \pm 0.1052$ & & \\
\hline & $\mathrm{N}_{3}$ & $4(12.9 \%)$ & $0.3824 \pm 0.0782$ & & \\
\hline \multirow[t]{4}{*}{ TNM stage } & II & $5(16.1 \%)$ & $0.3179 \pm 0.1862$ & $H=6.409$ & 0.093 \\
\hline & II & $2(6.5 \%)$ & $0.2257 \pm 0.0226$ & & \\
\hline & III & $16(51.6 \%)$ & $0.3951 \pm 0.1461$ & & \\
\hline & IV & $8(25.8 \%)$ & $0.4207 \pm 0.0882$ & & \\
\hline \multirow[t]{2}{*}{ Lymphatic vessel infiltration } & positive & $18(58.1 \%)$ & $0.5013 \pm 0.1412$ & $Z=-2.142$ & 0.040 \\
\hline & negative & $13(41.9 \%)$ & $0.3343 \pm 0.1212$ & & \\
\hline \multirow[t]{2}{*}{ Vascular infiltration } & positive & $17(54.8 \%)$ & $0.4783 \pm 0.1081$ & $Z=-2.042$ & 0.039 \\
\hline & negative & $14(45.2 \%)$ & $0.3343 \pm 0.1212$ & & \\
\hline \multirow[t]{2}{*}{ Ki-67 LI } & Lower & $16(51.6 \%)$ & $0.4364 \pm 0.1398$ & $Z=-2.332$ & 0.02 \\
\hline & higher & $15(48.4 \%)$ & $0.3164 \pm 0.1174$ & & \\
\hline
\end{tabular}

*: $\mathrm{N}_{0}$ vs $\mathrm{N}_{1-3} ; \mathrm{N}_{1-3}=\mathrm{N}_{1}+\mathrm{N}_{2}+\mathrm{N}_{3}=0.4266 \pm 0.1320$.

appearances. As reported [6], the initiation and the proliferation of colorectal cancer were based on CSCs with CD133 positive only in minor quantity, which was also identified not only in prostate [8], pancreatic [11] and hepatocellular [12] cancers but also in gastric cancer $[12,19]$. In this study of ours, CD133 protein positive structures had been seen in $29.3 \%$ cases in primary lesion of 99 patients' group, but no CD133 positive structures in NCGT. Simultaneously, CD133 mRNA expression had been identified in all primary lesions of 31 patients' group, but only $16.1 \%$ cases in NCGT of this same group. As compared with the level of CD133 mRNA BSV in NCGT, this value was significantly higher in primary lesion. Additionally, CD133 expression significantly correlated with tumor diameter of $>5 \mathrm{~cm}$, later TNM stage and $\mathrm{T}_{3}-\mathrm{T}_{4}$ as stratified analysis. Furthermore, either severer invasion depth or later TNM stage was the independent risk factor for CD133 protein expression. Therefore, it can be concluded from the above mentioned results that the tumor cells with CD133 protein and CD133 mRNA may play some important roles in the growth and the invasion of GC in human being.
Hermann PC et al [11] demonstrated that a subpopulation of migrating CSCs with both CD133 positive and CXCR4 positive was essential for tumor metastasis of pancreatic adenocarcinoma. Mehra N et al [20] examined whether RNA expressions of CD133 and CD146, a panendothelial marker, were increased in the blood of cancer patients and whether these factors correlated with patient characteristics and were predictive factors of survival. Their results in the peripheral blood mononuclear cells of 131 progressive cancer patients, 37 healthy volunteers, and 5 patients who received granulocyte colony-stimulating factor showed that patients with metastatic disease had a significant increase in CD133 mRNA $(P=0.03)$, specifically patients with bone metastasis $(P<0.001)$. In a recent study, it had been examined whether increased levels of expression of CD133 mRNA by semi-quantitative realtime RT-PCR analysis in peripheral blood predicted disease recurrence in patients with colon cancer. Their results indicated that elevated CD133 mRNA levels predicted colon cancer recurrence as an independent factor in Stage IV of TNM disease [21]. Similarly, the higher level of CD133 mRNA in primary lesion occurred in 


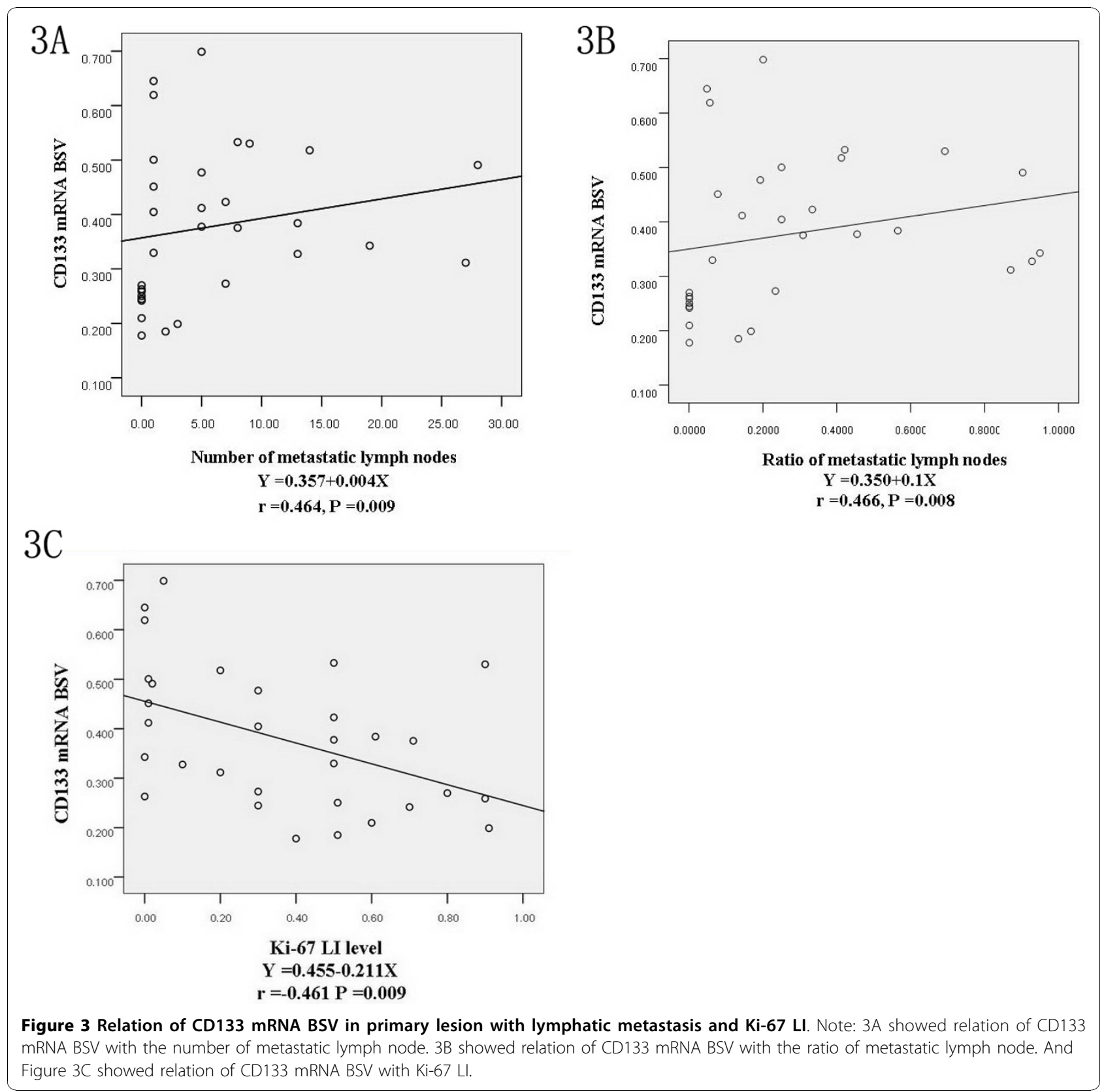

subgroup with lymph node metastasis, and this elevated level was positively relevant to the increments of metastatic lymph node ratio or metastatic lymph node number as demonstrated in our results of this study. Additionally, CD133 positive cells in cancerous emboli in vessel-like structures had been observed morphologically as a first report in our knowledge. In the immunohistochemical investigation in this study, CD133 positive percentage in subgroup of lymph node metastasis was significantly higher than that in subgroup without lymph node metastasis. With the increments of tumor invasion depth and TNM stage, CD133 protein positivity rate increased. From such results, it can be concluded that the positive expressions of CD133 mRNA and CD133 protein positively related to the lymphatic metastasis in GC, which can reasonably be considered as a risk factor to lymphatic metastasis and tumor invasion. Hence, the strategies aimed at the CD133 and SDF-1/CXCR4 modulating axis, and the molecular pathway for lymphatic metastasis may have important clinical significances to inhibit metastasis of CSCs.

$\mathrm{Ki}-67$ is a kind of nuclear protein, which expresses in cellular cycle of $G_{1}, S, G_{2}$ and $M$ phases, but not in $G_{0}$ phase. In order to probe the relation of $\mathrm{CD} 133$ expression 


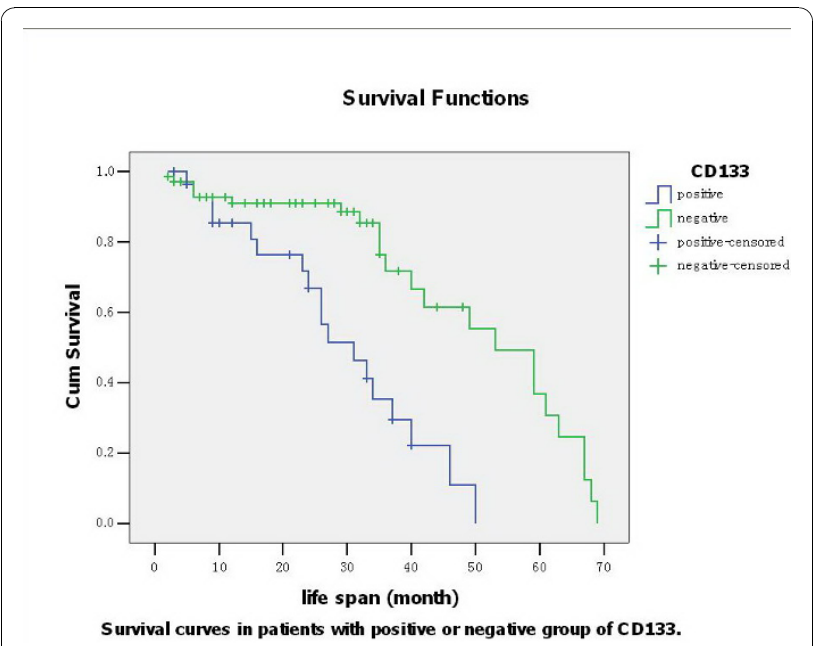

Figure 4 Survival curves in different groups of CD133 protein immunostaining. Note: $P=0.000$ by Log rank analysis.

with the proliferation of tumor cells with or without CD133 positivity, the CD133 mRNA expressive level was applied in this study due to the rare CSCs (usually around $1 \%-5 \%$ of total tumor cells) with CD133 protein positivity in tumor as common and the difficulty to identify CSCs as immature tumor cells from matured tumor cells morphologically. From current limited information indicated in this investigation of ours, there occurred the significantly higher expression of CD133 mRNA in subgroup with lower Ki-67 LI in comparison with that in subgroup with higher Ki-67 LI. Theoretically, this phenomenon observed in our study could be elucidated as the various biological profiles in different stage of tumor differential process or in proliferating characterization in the early stage of carcinogenesis and tumor development. And this proliferating characterization would be gradually weakened in tumor development probably. Additionally, in some extent, this higher expression of CD133 mRNA in subgroup with lower Ki-67 LI could also be explained to the resistant potential of CSCs to anti-cancerous therapy because tumor cells in Phase $G_{0}$ such as most of CSCs were difficult to be killed by cytotoxin drugs and radiotherapy [18]. On the other hand, for other explanation of this interesting phenomenon with negative relation between CD133 mRNA and Ki-67 LI, as our consideration, it is also contributed to the different proliferating abilities of matured tumor cells and immature tumor cells of CD133 positivity with some characteristics of CSCs. As well known, CSCs possessed strong differentiation proficiency, but this proficiency might not mean strong proliferating ability, especially comparing with that of matured tumor cells with CD133 negative expression probably. As there occurred so many kinds of cells in primary lesion and the limitation of only morphological and immunohistochemical observations in this study, the investigation on the both expressions of CD133 and Ki-67 in the same tumor cells should be necessarily considered to carry out in future.

As reported, cancer patients with high CD133 mRNA expression, using a defined cutoff value, showed a decreased survival compared with patients with low or undetectable CD133 expression (21\% versus $45 \%$ cumulative survival, respectively, after 20 months; $P=0.01$ ). Among patients with metastasis to the bone, cumulative survival was only $22 \%$, compared with $61 \%$ for patients with low or undetectable CD133 levels $(P=0.004)$ [20]. Furthermore, multivariate analysis in their study showed that CD133 expression was an independent predictor for overall survival in patients with bone metastases [20]. At the same time, they compared the level of CD146 mRNA, a pan-endothelial marker, with the level of CD133. CD146 mRNA level was not increased in patients with cancer, nor did CD146 mRNA level correlate with clinical variables or survival [20]. In this study of ours, prognostic analysis based on the different subgroups with or without CD133 protein positivity was assessed by univariate and multivariate evaluations. Univariate assessment revealed that average survival time was $(22.76 \pm 13.476)$ months in CD133 positive subgroup while $(28.41 \pm 18.078)$ months in negative

Table 4 Survival analysis on CD133 protein expression and clinicopathological parameters by Cox model ( $\mathrm{n}=99$ cases)

\begin{tabular}{cccccccc}
\hline Parameter & B & SE & Wald & df & Sig. & Exp(B) & 95.0\%Cl for Exp(B) \\
\hline Gender & 0.021 & 0.009 & 0.623 & 1 & 0.159 & 1.135 & $0.315 \sim 1.872$ \\
Age(year) & 0.010 & 0.013 & 0.554 & 1 & 0.457 & 1.010 & $0.991 \sim 1.681$ \\
Tumor diameter $(\mathbf{c m})$ & -0.076 & 0.070 & 1.186 & 1 & 0.276 & 0.927 & $0.872 \sim 1.561$ \\
Invasion depth & 0.288 & 0.343 & 0.703 & 1 & 0.402 & 1.334 & $0.318 \sim 6.105$ \\
Histological grade & 0.001 & 0.182 & 0.000 & 1 & 0.994 & 1.001 & $1.169 \sim 4.669$ \\
Lymph node metastasis & 0.867 & 0.361 & 0.035 & 1 & 0.042 & 1.978 & $1.987 \sim 10.238$ \\
TNM stage & 0.739 & 0.479 & 0.249 & 1 & 0.046 & 2.187 & $1.889 \sim ; 15.312$ \\
Lymphatic vessel infiltration & 0.871 & 0.592 & 2.168 & 1 & 0.141 & 2.390 & $0.987 \sim 6.558$ \\
Vascular infiltration & 0.218 & 0.560 & 0.152 & 1 & 0.697 & 1.244 & $2.377 \sim 9.912$ \\
CD133 protein expression & 0.894 & 0.449 & 3.966 & 1 & 0.046 & 2.445 & $2.118 \sim 16.381$ \\
\hline
\end{tabular}


subgroup. Multivariate analysis showed that, excepting for lymph node metastasis occurrence and later stage of TNM, CD133 protein positivity was also an independent risk factor to survival. Obviously, the detection of CD133 tumor marker regarding as one of the markers of CSCs may be a useful and supplementary means to take a judgment to prognosis of GC.

\section{Conclusion}

The expressions of CD133 protein and CD133 mRNA correlated with severer lymph node metastasis and lower LI of Ki-67. Positive expression of CD133 protein indicated the poorer prognosis, which raised the possibility that CD133 positive cells might execute some functions to promote the lymphatic metastasis in patients with GC. However, the study about the CSCs, especially the tumor cells with CD133 positivity, is still in the initial stage in GC, and the biological profiles of CSCs of gastric cancer should be further investigated in novel diagnosis, more suitable treatment strategies including the application of gene therapy by CD133 target and prognostic judgment in order to improve the effect of treatment on gastric cancer.

\section{Acknowledgements}

This research is supported by grants of Science and Technology Committee of Shanghai (grant no. 094119623000 for BJJ) and Research Funds of Shanghai Jiao-tong University School of Medicine (grant no. 2007XJ032 for BJJ; 2009XJ21037 for JWY). All authors appreciate the exelent technique supports in immunohistochemichal observations from Dr Guang-ye Du. All authors read and approved the final manuscript for publication.

\section{Author details \\ 'Department of General Surgery, No. 3 People's Hospital, Shanghai Jiao-tong University School of Medicine, Shanghai 201900, China. '2Department of General Surgery, Henan Province People's Hospital, Zhengzhou, Henan 450000, China. ${ }^{3}$ Department of Pathology, No. 3 People's Hospital, Shanghai Jiao-tong University School of Medicine, Shanghai 201900, China. \\ ${ }^{4}$ Experimental Center, No. 3 People's Hospital, Shanghai Jiao-tong University School of Medicine, Shanghai 201900, China.}

\section{Authors' contributions}

PZ contributed in study design, definition of intellectual content, literature research, experimental studies, data acquisition, data analysis, statistical analysis and manuscript preparation. JGW and SHW contributed in literature research, study design and data analysis. PZ, JGW, XQL contributed in pathological and immunohistochemical observations. PZ, JGW, RQL contributed in RT-PCR analysis. STW contributed in technique supports in laboratory. XCN, JWY, and BJJ contributed in clinical managements. BJJ and JWY contributed in grants for this study, guarantor of integrity of the entire study, study concepts, study design and manuscript review. All authors read and approved the final manuscript for publication.

\section{Competing interests}

The authors declare that they have no competing interests.

Received: 11 October 2010 Accepted: 7 November 2010 Published: 7 November 2010

\section{References}

1. Jemal A, Siegel R, Ward E, Hao Y, Xu J, Murry T, Thun MJ: Cancer statistics, 2008. CA Cancer J Clin 2008, 58:71-96.
2. Crew KD, Neugut Al: Epidemiology of gastric cancer. W J Astroenterol 2006, 12:354-362.

3. Fidler IJ: Critical factors in the biology of human cancer metastasis: twenty-eighth G.H.A. Clowes memorial award lecture. Cancer Res 1990, 50:6130-6138.

4. Singh SK, Hawkins C, Clarke ID, Singh SK, Hawkins C, Clarke ID, Squire JA, Bayani J, Hide T, Henkelman RM, Cusimano MD, Dirks PB: Identification of human brain tumour initiating cells. Nature 2004, 432:396-401.

5. O'Brien CA, Pollett A, Gallinger S, Dick JE: A human colon cancer cell capable of initiating tumour growth in immunodeficient mice. Nature 2007, 445:106-110.

6. Ricci-Vitiani L, Lombardi DG, Pilozzi E, Biffoni M, Todaro M, Peschle C, De Maria R: Identification and expansion of human colon cancer-initiating cells. Nature 2007, 445:111-115.

7. Hemmati HD, Nakano I, Lazareff JA, Masterman-Smith M, Geschwind DH, Bronner-Fraser M, Kornblum HI: Cancerous stem cells can arise from pediatric brain tumors. Proc Natl Acad Sci USA 2003, 100:15178-15183.

8. Collins AT, Berry PA, Hyde C, Stower MJ, Maitland NJ: Prospective identification of tumorigenic prostate cancer stem cells. Cancer Res 2005, 65:10946-10951.

9. Neuzil J, Stantic M, Zobalova R, Chladova J, Wang X, Prochazka L, Dong L, Andera L, Ralph SJ: Tumour-initiating cells vs. cancer 'stem' cells and CD133: what's in the name? Biochem Biophys Res Commun 2007, 355:855-859.

10. Tang C, Ang BT, Pervaiz S: Cancer stem cells: target for anti-cancer therapy. FASEB J 2007, 21:3777-3785.

11. Hermann PC, Huber SL, Herrier T, Aicher A, Ellwart JW, Guba M, Bruns CJ, Heeschen C: Distinct populations of cancer stem cells determine tumor growth and metastatic activity in human pancreatic cancer. Cell Stem Cell 2007, 1:313-323.

12. Smith $L M$, Nesterova $A$, Ryan $M C$, Duniho $S$, Jonas $M$, Anderson $M$, Zabinski RF, Sutherland MK, Gerber HP, Van Orden KL, Moore PA, Ruben SM, Carter PJ: CD133/prominin-1 is a potential therapeutic target for antibody-drug conjugates in hepatocellular and gastric cancers. $\mathrm{Br} J$ Cancer 2008, 99:100-109.

13. Yu JW, Wu JG, Zheng LH, Zhang B, Ni XC, Li XQ, Jiang BJ: Influencing factors and clinical significance of the metastatic lymph nodes ratio in gastric adenocarcinoma. Exp Clin Cancer Res 2009, 26:55.

14. Joo YE, Chung IJ, Park YK, Koh YS, Lee JH, Park CH, Lee WS, Kim HS, Choi SK, Rew JS, Park CS, Kim SJ: Expression of cyclooxygenase-2, p53 and Ki-67 in gastric cancer. J Korean Med Sci 2006, 21:871-876.

15. International Union Against Cancer (UICC): TNM classification of malignant tumours.Edited by: Sobin LH, Gospodarowicz MK, Wittekind C. WileyBlackwell, New York, USA; , 72009.

16. Miraglia S, Godfrey W, Yin AH, Atkins K, Warnke R, Holden JT, Bray RA Waller EK, Buck DW: A novelfive-transmembrane hematopoietic stem cell antigen: isolation, characterization, and molecular cloning. Blood 1997, 90:5013-5021.

17. Suetsugu $A$, Nagaki M, Aoki H, Motohashi T, Kunisada T, Moriwaki $H$ : Characterization of CD133+ hepatocellular carcinoma cells as cancer stem/progenitor cells. Biochem Biophys Res Commun 2006, 351:820-824.

18. Gangemi R, Paleari L, Orengo AM, Cesario A, Chessa L, Ferrini S, Russo P. Cancer stem cells: A new paradigm for understanding tumor growth and progression and drug resistance. Curr Med Chem 2009, 16:1688-1703.

19. Katoh $Y$, Katoh M: Comparative gemomics on PROM1 gene encoding stem cell marker CD133. Int J Mol Med 2007, 19:967-970.

20. Mehra N, Penning M, Maas J, Beerepoot LV, van Daal N, van Gils CH, Giles RH, Voest EE: Progenitor marker CD133 mRNA is elevated in peripheral blood of cancer patients with bone metastases. Clin Cancer Res 2006, 12:4859-4866.

21. Lin EH, Hassan M, Li Y, Zhao H, Nooka A, Sorenson E, Xie K, Champlin R, Wu X, Li D: Elevated circulating endothelial progenitor marker CD133 messenger RNA levels predict colon cancer recurrence. Cancer 2007, 110:534-542

doi:10.1186/1756-9966-29-141

Cite this article as: Yu et al.: Expressions and clinical significances of CD133 protein and CD133 mRNA in primary lesion of gastric adenocacinoma. Journal of Experimental \& Clinical Cancer Research 2010 29:141. 